\title{
The changing trends of image-guided biopsy of small renal masses before intervention-an analysis of European multinational prospective EURECA registry
}

\author{
Vinson Wai-Shun Chan ${ }^{1}$ • Francis Xavier Keeley $\mathrm{Jr}^{2} \cdot$ Brunolf Lagerveld $^{3}$ - David J. Breen ${ }^{4}$. Alexander King ${ }^{4}$. \\ Tommy Kjærgaard Nielsen ${ }^{5}$. Marco van Strijen ${ }^{6}$. Julien Garnon ${ }^{7}$. Des Alcorn ${ }^{8}$. Ole Graumann ${ }^{9}$ • Eric de Kerviler ${ }^{10}$. \\ Patricia Zondervan ${ }^{11} \cdot$ Miles Walkden ${ }^{12} \cdot$ Giovanni Lughezzani $^{13} \cdot$ Tze Min Wah $^{14}$ (D)
}

Received: 16 September 2021 / Revised: 1 December 2021 / Accepted: 26 December 2021 / Published online: 5 February 2022

(C) The Author(s) 2022

\begin{abstract}
Objectives To evaluate the use of pre-cryoablation biopsy for small renal masses (SRMs) and the effects of increasing uptake on histological results of treated SRMs.

Methods From 2015 to 2019, patients with sporadic T1N0M0 SRMs undergoing percutaneous, laparoscopic, or open cryoablation from 14 European institutions within the European Registry for Renal Cryoablation (EuRECA) were included for the retrospective analysis. Univariate and multivariate logistic models were used to evaluate the trends, histological results, and the factors influencing use of pre-cryoablation biopsy.

Results In total, 871 patients (median (IQR) age, 69 (14), 298 women) undergoing cryoablation were evaluated. The use of precryoablation biopsy has significantly increased from 42\% (65/156) in 2015 to $72 \%(88 / 122)$ in $2019(p<0.001)$. Patients treated for a benign histology are significantly more likely to have presented later in the trend, where pre-cryoablation biopsy is more prevalent (OR: $0.64,95 \%$ CI $0.51-0.81, p<0.001)$. Patients treated for undiagnosed histology are also significantly less likely to have presented in 2018 compared to 2016 (OR $0.31,95 \%$ CI $0.10-0.97, p=0.044$ ). Patients aged $70+$ are less likely to be biopsies pre-cryoablation $(p<0.05)$. R.E.N.A.L. nephrometry score of $10+$ and a Charlson Comorbidity Index $>1$ are factors associated with lower likelihood to not have received a pre-cryoablation biopsy $(p<0.05)$.

Conclusion An increased use of pre-cryoablation biopsy was observed and cryoablation patients treated with a benign histology are more likely to have presented in periods where pre-cryoablation biopsy is not as prevalent. Comparative studies are needed to draw definitive conclusions on the effect of pre-cryoablation biopsy on SRM treatments.
\end{abstract}

Tze Min Wah

tze.wah@nhs.net

1 School of Medicine, Faculty of Medicine and Health, University of Leeds, Leeds, UK

2 Bristol Urological Institute, North Bristol NHS Trust, Bristol, UK

3 Department of Urology, OLVG, Amsterdam, the Netherlands

4 Department of Radiology, Southampton University Hospitals, Southampton, UK

5 Department of Urology, Aarhus University Hospital, Aarhus, Denmark

6 Department of Radiology, St. Antonius Hospital, Nieuwegein, the Netherlands

7 Department of Interventional Radiology, Nouvel Hôpital Civil, 1 place de l'Hôpital, 67000 Strasbourg, France
8 Department of Interventional Radiology, Gartnavel General Hospital, Glasgow, UK

9 Department of Radiology, Odense University Hospital, Odense, Denmark

10 Radiology Department, Saint-Louis Hospital, AP-HP, 1 avenue Claude-Vellefaux, 75475 Paris cedex 10, France

11 Department of Urology, 26066Amsterdam UMC, University of Amsterdam, Amsterdam, the Netherlands

12 Department of Imaging, University College London Hospitals NHS Foundation Trust, London, UK

13 Department of Urology, Vita-Salute San Raffaele University, Milan, Italy

14 Department of Diagnostic and Interventional Radiology, Institute of Oncology, St. James's University Hospital, Leeds Teaching Hospitals NHS Trust, Leeds LS9 7TF, UK 


\section{Key Points}

- The use of biopsy pre-ablation session has increased significantly from $42 \%$ of all patients in 2015 to $74 \%$ in 2019.

- Patients are less likely to be treated for a benign tumour if they presented later in the trend, where pre-cryoablation biopsy is more prevalent, compared to later in the trend (OR 0.64, 95\% CI 0.51-0.81, $p<0.001)$.

- Patients with comorbidities or a complex tumour (R.E.N.A.L. nephrometry score > 10) are less likely to not undergo biopsy as a separate session to cryoablation.

Keywords Image-guided biopsy $\cdot$ Cryoablation $\cdot$ Renal cell carcinoma $\cdot$ Kidney neoplasms

$\begin{array}{ll}\text { Abbreviations } \\ \text { CCI } & \text { Charlson Comorbidity Index } \\ \text { CT } & \text { Computed tomography } \\ \text { EAU } & \text { European Association of Urology } \\ \text { eGFR } & \text { Estimated glomerular filtration rate } \\ \text { EuRECA } & \text { European Registry for Renal Cryoablation } \\ \text { IQR } & \text { Interquartile range } \\ \text { MRI } & \text { Magnetic resonance imaging } \\ \text { RCC } & \text { Renal cell carcinoma } \\ \text { SRM } & \text { Small renal mass } \\ \text { US } & \text { Ultrasound }\end{array}$

\section{Introduction}

Renal cancer makes up approximately $2 \%$ of all cancers worldwide [1], accounting to almost 40,000 deaths within the European Union in 2018 [2]. The increase in incidental detection of small renal masses (SRMs) over the last decade was said to be attributed to increased routine imaging [3]; the common managements for SRMs include partial nephrectomy, image-guided ablation, and active surveillance, but the optimal diagnostic pathways for SRMs are, however, constantly debated. Currently, the diagnosis of renal tumours is largely based on contrast-enhanced imaging such as computed tomography (CT) or magnetic resonance imaging (MRI) [4]. However, concerns of overtreating benign tumours have arisen due to the high percentage of benign tumours in patients presenting with SRMs. In surgical patients, a large study of 18,060 patients undergoing partial nephrectomy suggested a benign rate as high as $30 \%$ [5], while the benign rate can be as high as $26 \%$ in mixed treatment patients [6].

A long-term experience by Richard et al found pretreatment biopsies to be $90 \%$ diagnostic, with $26 \%$ having benign histology [6]. Similarly, a multicentre study has concluded that routine biopsies reveal significantly lower rates of benign tumours when compared to selected biopsies at the time of surgery [7]. Previous reports of pre-ablation biopsy of small renal tumours showed a benign rate of $18.2 \%$, while a comparator group undergoing biopsy at the time of ablation had a benign rate of $16.8 \%$ [8]. These study results has led to the consideration of significant overtreatment and unnecessary surgery for patients with benign tumours as most benign tumours can be safely observed under surveillance due to slow growth rates [9]. In concordance, the latest update of the European Association of Urology (EAU) guidelines strongly suggests the performance of percutaneous renal mass biopsy prior to ablative therapies prior to, but not concomitantly with ablation [10].

A recent meta-analysis by Marconi et al has established the high diagnostic yield and safety profile of image-guided percutaneous biopsy in 2016 [11]; however, the resistance within the urological community to perform renal tumour biopsy remains apparent, due to concerns on the effects of biopsies on altering management plans [12]. Hence, this study, utilising a multicentre European prospectively maintained database, aims to investigate the trends of biopsies pre-cryoablation and their histological results in the past 6 years, and the potential factors influencing the decision to perform image-guided biopsies before active treatment.

\section{Methods and materials}

\section{Patient selection}

Institutional review board approval and patient consent were not required for this registry-based study. The prospectively maintained multicentre European Registry for Renal Cryoablation (EuRECA) [13] was retrospectively enquired to identify patients with primary, sporadic, and localised cT1aN0M0 or cT1bN0M0 SRMs treated by percutaneous, laparoscopic, or open cryoablation at 14 centres around Europe from 2014 to 2020. Patients with cT1a renal masses were defined as a maximum tumour diameter of $\leq 4 \mathrm{~cm}$ while cT1b renal masses were defined as $>4 \mathrm{~cm}$ and $\leq 7 \mathrm{~cm}$ on radiographic imaging according to the American Joint Committee on Cancer (AJCC) staging manual [14]. Patients with multiple renal tumours, recurrences, and inherited renal cell carcinoma (RCC) syndromes were excluded from the analysis [15]. Patients with history of partial nephrectomy, cryoablation, or radiofrequency ablation of the same or contralateral kidney were also excluded from analysis. Due to lack of a full year data, and the COVID-19 pandemic [16-18], patients in 2014 and 2020 were excluded from the 
analysis. Patients with missing histological results are included in the primary objective, but not the secondary outcome.

\section{Clinical features and covariates}

Patient clinical features including age, sex, race, comorbidities (Charlson Comorbidity Index [CCI] [19]), clinical history, and body mass index were analysed. The baseline estimated glomerular filtration rate (eGFR) derived using the formula from the Modification of Diet in Renal Disease (MDRD) cohort [20] was also collected. Tumour characteristics such as maximum diameter as well as the components of R.E.N.A.L. nephrometry score [21] were collected to identify potential factors influencing the decision of performing precryoablation biopsies.

\section{Diagnosis and biopsy}

Patients were diagnosed of small renal tumours on imaging with either CT, MRI, or ultrasound (US). Patients were then selected to undergo pre-treatment biopsy as a separate session to the treatment session by a multidisciplinary team consisting of urologists, oncologists, and radiologists. Pre-cryoablation biopsies were performed under imaging guidance (US, CT, or MRI). Considering the results from the biopsy (if available), patient's condition, and preferences, patients were then selected by the multidisciplinary team to undergo cryoablation, other treatments, or active surveillance. Patients with no precryoablation biopsies were biopsied during the cryoablation session using an automated, Tru Cut or suction core device before cryoablation. All biopsies were examined by pathologists at each institution. Biopsies were defined as malignant, benign, and undiagnosed (no classification or normal renal tissue).

\section{Outcomes and statistical analysis}

The primary outcome of the study is to assess the trend of performing image-guided biopsy before cryoablation and the effects of the trend on proportion of patients receiving a definitive pathological diagnosis. The secondary outcome aims to identify potential factors influencing the decision to perform image-guided biopsy before cryoablation. Bar graphs and line charts were utilised to illustrate the change in trend from 2015 to 2019. Univariate logistic regression and chisquared test were used to assess the effect of the changing trend on performance of pre-cryoablation biopsies and their histological results. Univariate logistic regression and multivariate logistic regression of clinically relevant parameters were performed, taking into account potential confounding biases to assess the factors influencing decision to perform pre-cryoablation biopsy. Both $t$-tests and chi-square tests were utilised to compare baseline characteristics of all patients. All analyses were two-tailed at a significance level of 0.05 and were performed using STATA 16 (Stata Corp) and Microsoft Excel (Microsoft Corp). This study is conducted according to the "Strengthening the Reporting of Observational Studies in Epidemiology" (STROBE) guidelines [22].

\section{Results}

\section{Baseline characteristics of included patients}

A total of 1327 patients from 14 high-volume, experienced academic centres (Supplementary Table 1) across Europe were included. After applying inclusion and exclusion criteria (Figure 1), 871 patients remained for the retrospective analysis. Out of the 871 patients, $555(64 \%$; 555/871) received a pre-cryoablation biopsy, whereas $316(36 \% ; 316 / 871)$ did not. The clinical pathologic details of these patients are outlined in Table 1. Amongst the full cohort, 573 are male and 298 are female, dominated by a Caucasian population $(96 \% ; 836 /$ 871). The median (IQR) age of the cohort is $69(61-75)$. A majority of the patients had T1a disease $(82.1 \% ; 715 / 871)$ and $18 \%$ (156/871) had T1b disease. The median (IQR) tumour size of the cohort is $3 \mathrm{~cm}(2.2-3.6)$, with a median (IQR) R.E.N.A.L. nephrometry score of 7 (5-8). A total of $4 \%$ (37/ 871) of patients has a solitary functional kidney due to noncancer causes. The median (IQR) CCI of the cohort is $2(0-3)$ with a median baseline eGFR of $85.4(65.09-107.80) \mathrm{ml} / \mathrm{min} /$ $1.73 \mathrm{~m}^{2}$.

\section{Trends of pre-cryoablation biopsy}

A trend of significantly increasing use of pre-cryoablation biopsy was observed between the period of 2015 and 2019 amongst all T1 diseases (Figure 2a; Table 2). The utilisation of pre-cryoablation biopsy has risen from 42\% (65/156) in 2015 to $74 \%(79 / 107)$ in $2019(p<0.001)$, with a similar trend observed in T1a disease alone (Figure 2b). In T1b disease, the use of pre-cryoablation biopsy rose steadily from 2015 to 2018 and declined in 2019. While the trend does not follow that of $\mathrm{T} 1$ and $\mathrm{T} 1 \mathrm{a}$, general increase of usage of precryoablation biopsies for $\mathrm{T} 1 \mathrm{~b}$ tumours has been observed (Figure 2c). Table 2 shows the breakdown of number of biopsies by year and the results of univariate logistic regression to identify the changing trends in the use of pre-cryoablation biopsy; notably, year by year, patients treated after 2015 are significantly more likely to have received pre-cryoablation biopsy when compared with those who received treatment in 2015. 
Table 1 Clinical and pathological features of included patients

\begin{tabular}{|c|c|c|c|c|c|}
\hline \multirow[t]{2}{*}{ Variable } & \multicolumn{2}{|c|}{$\begin{array}{l}\text { Presented from } 2015 \text { to } 2016 \\
(n=348)\end{array}$} & \multicolumn{2}{|c|}{$\begin{array}{l}\text { Presented from } 2017 \text { to } 2020 \\
(n=523)\end{array}$} & \multirow[b]{2}{*}{$p$ value } \\
\hline & Frequency & $\%$ & Frequency & $\%$ & \\
\hline \multicolumn{6}{|l|}{ Age } \\
\hline$<50$ & 29 & 8.3 & 32 & 6.1 & \multirow[t]{6}{*}{0.451} \\
\hline $50-59$ & 43 & 12.4 & 69 & 13.2 & \\
\hline $60-69$ & 108 & 31.0 & 167 & 31.9 & \\
\hline $70-79$ & 125 & 35.9 & 194 & 37.1 & \\
\hline $80-89$ & 41 & 11.8 & 61 & 11.7 & \\
\hline$>90$ & 2 & 0.6 & 0 & 0.0 & \\
\hline \multicolumn{6}{|l|}{ Sex } \\
\hline Male & 231 & 66.4 & 342 & 65.79 & \multirow[t]{2}{*}{0.764} \\
\hline Female & 1117 & 33.62 & 181 & 34.21 & \\
\hline \multicolumn{6}{|l|}{ Race } \\
\hline Caucasian & 325 & 93.4 & 511 & 97.7 & \multirow[t]{3}{*}{0.002} \\
\hline Asian & 9 & 2.6 & 8 & 1.5 & \\
\hline Black & 14 & 4.0 & 4 & 0.8 & \\
\hline \multicolumn{6}{|l|}{ T-stage (T1a/T1b) } \\
\hline T1a & 284 & 81.6 & 431 & 82.4 & \multirow[t]{2}{*}{0.763} \\
\hline $\mathrm{T} 1 \mathrm{~b}$ & 64 & 18.48 & 92 & 17.6 & \\
\hline \multicolumn{6}{|l|}{ Solitary kidney } \\
\hline Yes & 15 & 4.3 & 22 & 4.2 & \multirow[t]{2}{*}{0.941} \\
\hline No & 333 & 95.7 & 501 & 95.8 & \\
\hline \multicolumn{6}{|l|}{ Received pre-cryoablation biopsy } \\
\hline Yes & 170 & 48.9 & 385 & 73.6 & \multirow[t]{2}{*}{$<0.001$} \\
\hline No & 178 & 51.2 & 138 & 26.4 & \\
\hline \multicolumn{6}{|l|}{ Histology } \\
\hline Malignant & 273 & 82.2 & 438 & 91.1 & \multirow[t]{4}{*}{$<0.001$} \\
\hline Benign & 36 & 10.8 & 20 & 4.2 & \\
\hline Undiagnosed & 23 & 6.9 & 23 & 4.8 & \\
\hline Missing & 18 & & 51 & & \\
\hline Variable & Median & IQR & Median & IQR & $p$ value \\
\hline Tumour size (cm) & 3.0 & $2.3-3.6$ & 3.0 & $2.2-3.6$ & 0.563 \\
\hline R.E.N.A.L. nephrometry score & 7 & $5-8$ & 7 & $5-8$ & 0.784 \\
\hline Charlson Comorbidity Index & 2 & $0-3$ & 2 & $1-3$ & 0.027 \\
\hline Baseline eGFR & 95.2 & $68.3-150.0$ & 82.1 & $64.2-97.7$ & $<0.001$ \\
\hline
\end{tabular}

CRYO cryoablation, $e G F R$ estimated glomerular filtration rate

Bolded $p$ value suggests significance to the level of 0.05

\section{Histological results of biopsies in relation to time and utilisation of pre-cryoablation biopsy: pre- cryoablation vs at the time of cryoablation}

The diagnostic process and the histological results of the 871 included patients are outlined in Figure 3 and Supplementary Table 2. Amongst the 871 patients, 33 had missing histological data and were excluded from the analysis. Twenty-five patients did not receive a biopsy at the time of cryoablation and was therefore also excluded from the analysis. Amongst the 813 remaining patients, those who presented later in the trend had significantly higher rate of malignancy as compared to those who presented earlier in the trend (OR 1.33, 95\% CI $1.12-1.58, p=0.001$ ). Similarly, patients who presented later in the trend had significantly lower rate of benign histology as compared to those who presented earlier in the trend (OR $0.64,95 \%$ CI $0.51-0.81, p<0.001)$. When comparing the periods of increasing adoption, patients are less likely to receive cryoablation for undiagnosed biopsies (OR 0.31, 95\% CI $0.10-0.97, p=0.044$ ) in 2018, using 2016 as a baseline. However, when spanning the full study period from 2015 to 2019 , the difference is insignificant (OR $0.93,95 \%$ CI 0.74 
Fig. 1 Flow diagram representing the patient selection process

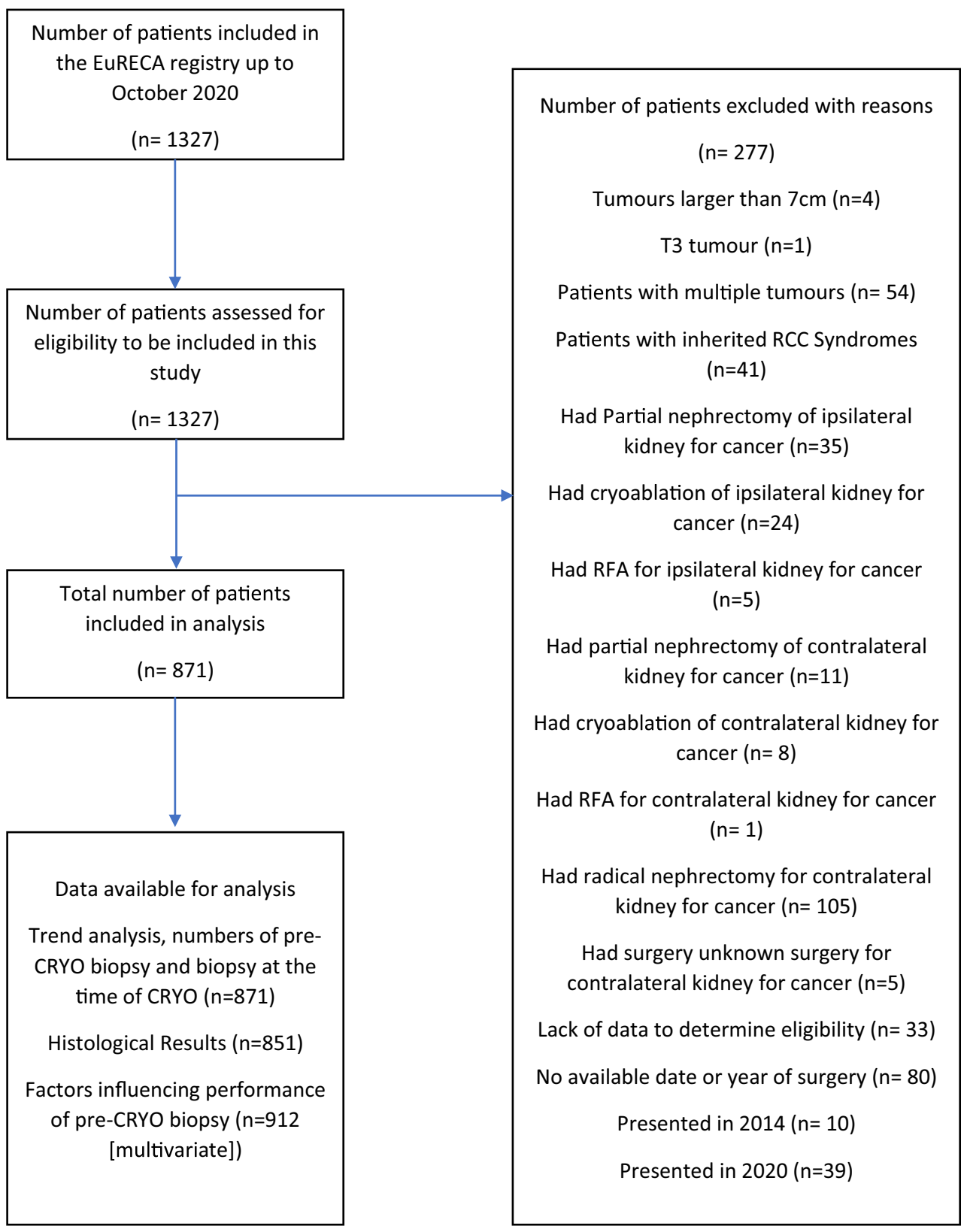

$1.18, p=0.554)$, given the anomalously low undiagnosed rate in 2015. The full categorical logistic regression and breakdown of histological outcome per year are shown in Table 3.

Overall, 6.9\% (66/813) and 5.7\% (46/813) patients had a benign or undiagnostic histology results, respectively, suggesting a total combined undiagnosed or benign rate of $12.6 \%(102 / 831)$. This rate has decreased significantly from $20.9 \%(31 / 148)$ in 2015 to $5.7 \%(10 / 174)$ in $2018(p<0.001)$.

\section{Factors influencing performance of pre-cryoablation biopsy}

Univariate and multivariate logistic regressions were performed to identify potential factors influencing performance of pre- cryoablation ablation (Table 4). Amongst multivariate logistic regression of clinically relevant parameters, it was found that patients aged 70-79 (OR 2.17, 95\% CI 1.13-4.18, $p=0.020$ ) and 80-89 (OR 2.39, 95\% CI 1.14-5.02, $p=0.021)$ are more likely to have not received pre-cryoablation biopsy. In reverse, those with a CCI greater than 1 (OR 0.40, 95\% CI 0.28-0.57, $p<0.001)$ or with a R.E.N.A.L. nephrometry score of 10-12 (OR $0.45,95 \%$ CI $0.25-0.84, p=0.011$ ) are less likely to have not received a pre-cryoablation biopsy. When exploring R.E.N.A.L. nephrometry by its components, patients with posterior tumours (OR 0.48, 95\% CI 0.34-0.68, $p<0.001$ ) or tumours that are less than $50 \%$ exophytic (OR $0.67,95 \% \mathrm{CI}$ $0.50-0.91, p=0.010$ ) or entirely endophytic (OR $0.55,95 \%$ CI $0.37-0.84, p=0.005$ ) or are not touching renal artery or 
(a)

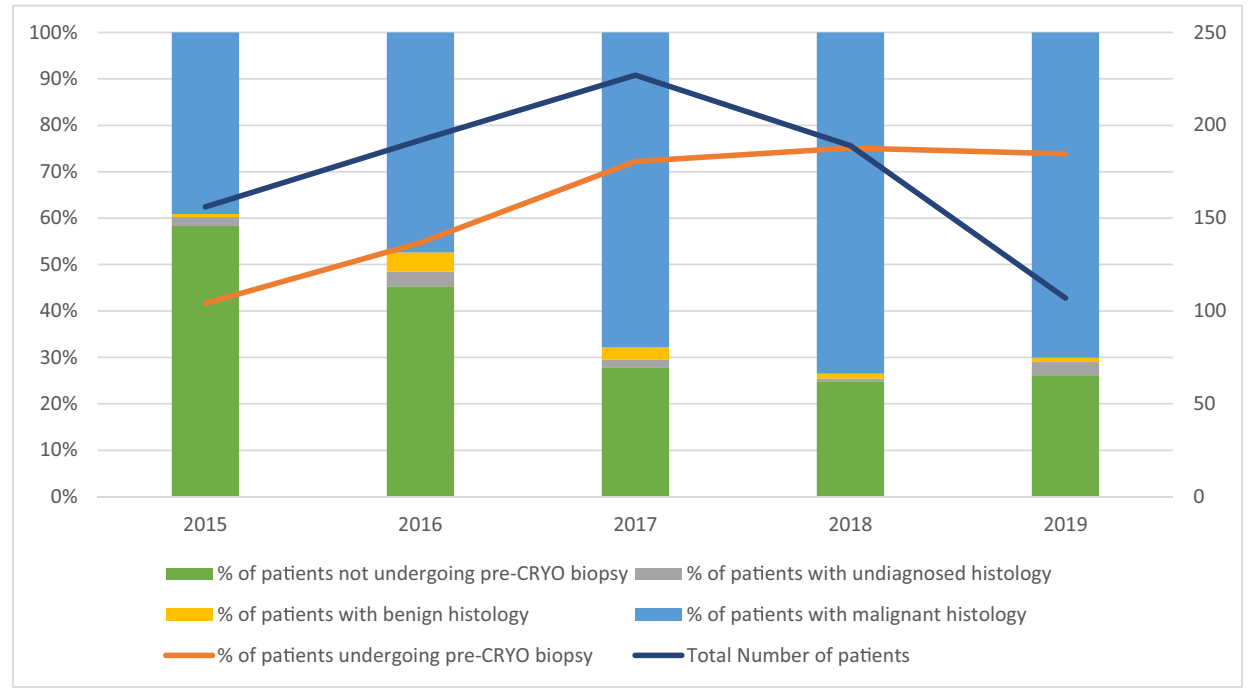

(b)

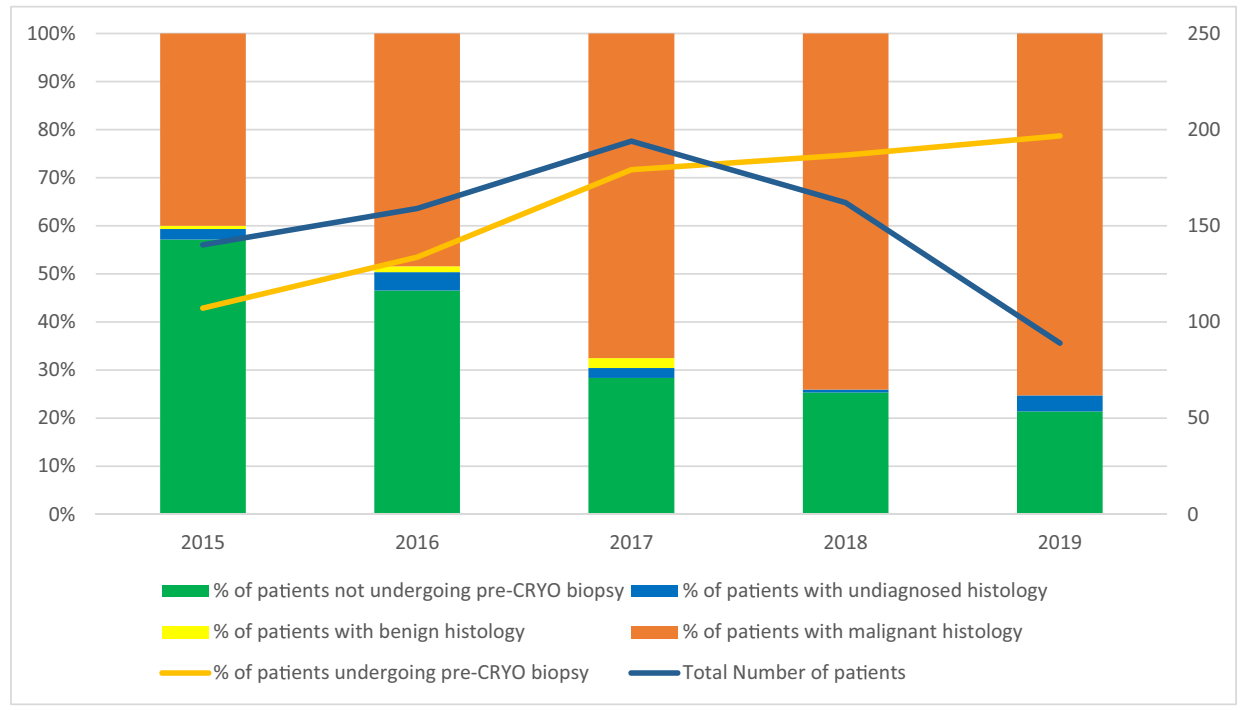

(c)

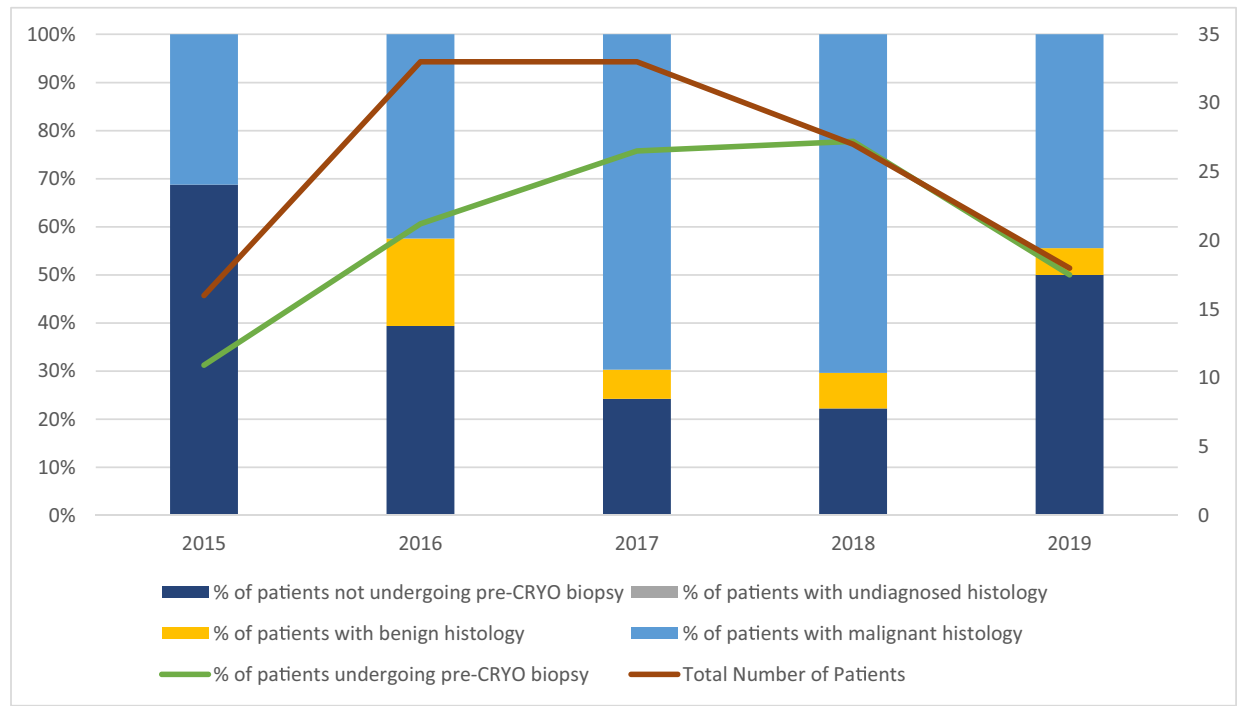


Fig. 2 Trends of performance of pre-cryoablation biopsy and the results of histological results from 2014 to 2020 in (a) T1 disease, (b) T1a disease, and (c) T1b disease

vein (OR $0.30,95 \%$ CI $0.19-0.50, p<0.001)$ are less likely to be not biopsied pre-cryoablation. Tumours that cross the polar line more than $50 \%$, crosses the axial line, and between the polar lines are also significantly less likely to be not biopsied before treatment (OR 0.64, 95\% CI 0.45-0.89, $p=0.008)$. Patients with lesions that were $\leq 4 \mathrm{~mm}$ from the collecting system or sinus are significantly more likely to not be biopsied $(1.85,95 \%$ CI $1.34-2.54, p<0.001)$. Logistic regression of R.E.N.A.L. score and patients' likelihood to receive precryoablation biopsy are outlined in Table 5. Other factors such as tumour diameter and baseline eGFR were not found to be associated with the odds of patients receiving pre-cryoablation biopsy.

\section{Discussion}

The EuRECA registry includes high-volume centres across Europe with considerable experience in renal biopsy. This study identified an important paradigm shift of the use of pre-cryoablation biopsy in the past half-decade as utilisation of pre-cryoablation biopsy has risen from $42 \%(65 / 156)$ in 2015 to $74 \%(79 / 107)$ in $2019(p<0.001)$, in concordance with the EAU's advocacy in performing pre-treatment biopsy in SRMs [10]. Other than more informative guidelines and patient-centred care, multiple studies suggesting the safety, diagnostic accuracy, as well as the potential benefits of performing pre-treatment biopsy [23-26] have led to an increase uptake of pre-treatment biopsy. Notably, Maturen et al concluded the definitive role of pre-cryoablation biopsy to significantly alter treatment decisions, especially in benign diseases where patients would have otherwise received a nephrectomy [25] and where low-grade tumours can be safely monitored by active surveillance. In the EuRECA registry, we found patients presented late in the trend, who are more likely to have received pre-cryoablation biopsy, to have a significantly lower benign rate compared to patients who did not (OR $0.64,95 \%$ CI $0.51-0.81, p=0.001$ ), suggesting a potentially significant role of pre-cryoablation biopsy to prevent treatment of patients with benign tumours, understanding that some patients may receive treatment for benign tumours due to their increasing size. In comparison to published data, cohorts not undergoing pre-treatment biopsy have a benign surgical histology of up to $30 \%[5,6]$ compared to $12.4 \%$ [32/ $258]$ in this cryoablation cohort. While pre-treatment biopsy may be regarded as an extra procedure, the risk of seeding haemorrhage and seeding is minimal. A systematic review reported only one case of transitional cell carcinoma seeding in 5228 biopsies performed, with a bleeding rate of $0.7 \%$ [11]. Furthermore, the benefits of renal tumour biopsy do not limit to informing a better treatment plan and to reducing overtreatment; pre-treatment biopsies can also increase the rates of patients receiving definitive histological confirmation after treatment. The EuRECA registry has shown a 15\% (39/258) rate of undiagnosed histology at first attempt of biopsy during cryoablation, suggesting these $15 \%$ of patients will not receive a histological confirmation. As opposed, if patients do have an undiagnosed pre-cryoablation biopsy, as shown in our data, only $1 / 11$ continued to have undiagnosed histology at the time of cryoablation, suggesting the advantage of the extra pre-cryoablation biopsy step in patient's treatment pathway. In light of these findings, this study hopes to serve as evidence for the EAU guidelines to recommend pre-ablation biopsy as an optimal step in the patient's RCC management.

Table 2 Performance of pre-cryoablation biopsy by year and results of univariate logistic regression

\begin{tabular}{llllllll}
\hline Year & $\begin{array}{l}\text { Number of pre- } \\
\text { CRYO biopsies } \\
\text { performed }\end{array}$ & $\%$ & $\begin{array}{l}\text { Number of } \\
\text { patients with no } \\
\text { pre-CRYO biopsy } \\
\text { performed }\end{array}$ & $\begin{array}{l}\text { Total number } \\
\text { of patients }\end{array}$ & OR (95\% CI) & $\begin{array}{l}p \text { value } \\
\text { (logistic } \\
\text { regression) }\end{array}$ & $\begin{array}{l}p \text { value } \\
\text { (chi-squared) }\end{array}$ \\
\hline 2015 & 65 & $41.7 \%$ & 91 & $58.3 \%$ & 156 & Ref. & $<$ \\
2016 & 105 & $54.7 \%$ & 87 & $45.3 \%$ & 192 & $1.69(1.10-2.59)$ & $\mathbf{0 . 0 1 6}$ \\
2017 & 164 & $72.2 \%$ & 63 & $27.8 \%$ & 227 & $3.64(2.37-5.61)$ & $<\mathbf{0 . 0 0 1}$ \\
2018 & 142 & $75.1 \%$ & 47 & $24.9 \%$ & 189 & $4.23(2.67-6.69)$ & $<\mathbf{0 . 0 0 1}$ \\
2019 & 79 & $73.8 \%$ & 28 & $26.2 \%$ & 107 & $3.95(2.31-6.75)$ & $<\mathbf{0 . 0 0 1}$ \\
Total & 555 & & 316 & & 971 & $1.51(1.35-1.70) *$ & $<\mathbf{0 . 0 0 1}$
\end{tabular}

$O R$ odds ratio, $C I$ confidence interval, $R e f$ reference, $N / A$ not applicable, $C R Y O$ cryoablation

*Analysed as with year of surgery as continuous variable across whole study period (2015-2019)

Bolded $p$ value suggests significance to the level of 0.05 


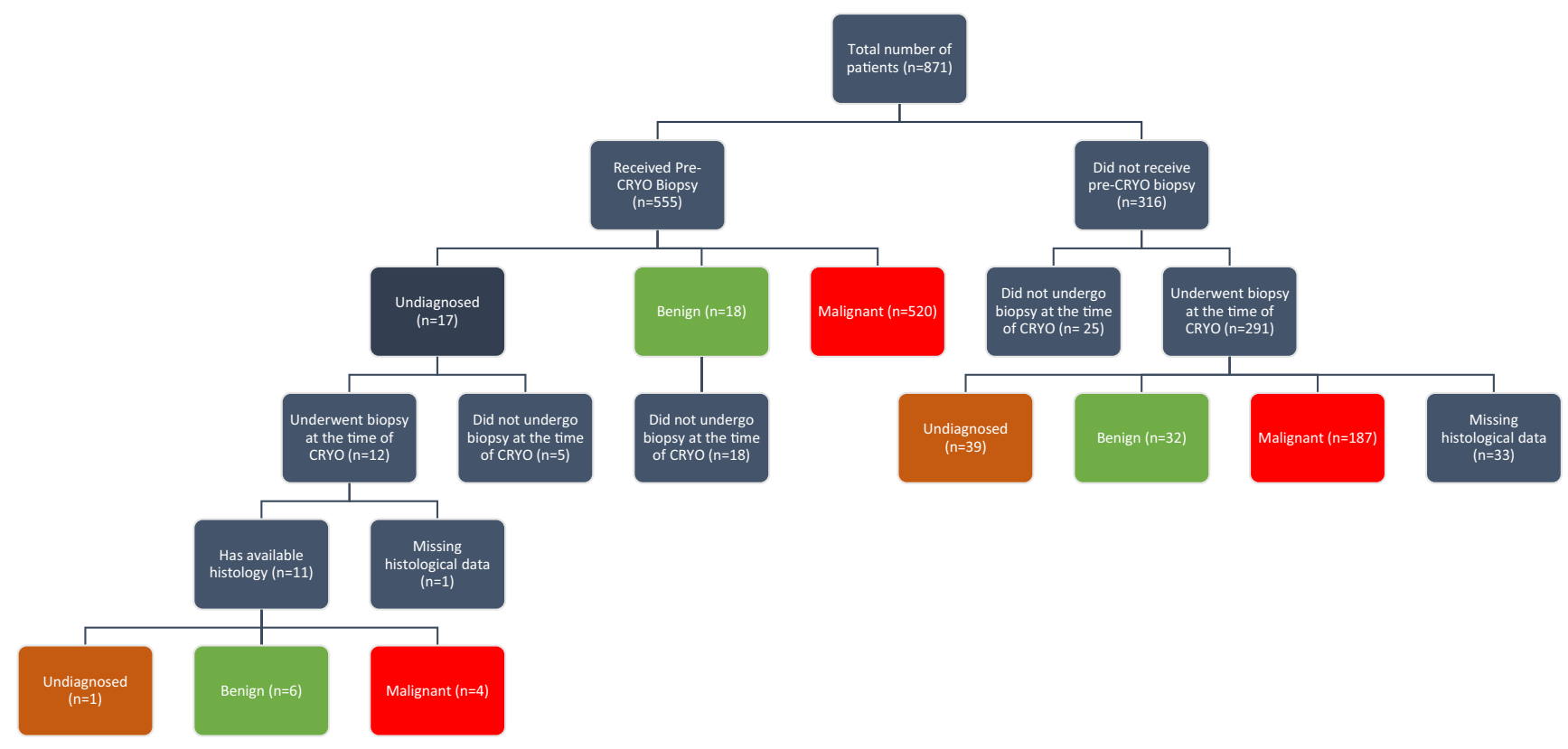

Fig. 3 Outline of the diagnostic process and histological results

A major strength of this study is the high volume and experience of the included centres. The overall undiagnosed or benign rate is $12.5 \%(102 / 813)$ in the EuRECA registry, which is significantly lower than previous reports $[5,6]$, although patients with benign tumours may have been excluded from cryoablation treatment in the EuRECA registry. Furthermore, the undiagnosed or benign detection rate has reduced over the years, suggesting a major improvement in the way patients were selected for biopsies and eventually for cryoablation. Our analysis suggests age to be a major factor in influencing the decision of performing a pre-cryoablation biopsy, especially amongst those in their $70 \mathrm{~s}$ or $80 \mathrm{~s}$. Understandably, these patients have lower RCC-specific mortality rates as a result of aging and other potential comorbidities, along with the potential risks to undergo pre-cryoablation biopsy; active surveillance should be advocated for such cases [27-30] as per EAU guidelines [10], as performing a biopsy will not significantly affect the management plan. On the contrary, our study has found patients with a CCI $>1$ are less likely not to have received a pre-cryoablation biopsy, while a pre-cryoablation biopsy may put comorbid patients through an extra procedure and cumulative risks; a benign histology may reduce the risk of patients having to receive a potential risk of general anaesthesia during cryoablation session, striking a balance on to treat or not to treat. Patients with a R.E.N.A.L. nephrometry score of over 10 are also less likely to not be biopsied due to the risk of complications associated with high nephrometry score during both nephrectomy and ablation [31, 32].
To our knowledge, this study is the first multicentre study in Europe to investigate the trends of pre-cryoablation biopsy and the factors influencing the performance of precryoablation biopsy. While the results may have provided some insightful and positive findings, it does not come without limitations. Firstly, the EuRECA database only captures data on patients who eventually undergo image-guided cryoablation; hence, this study is unable determine the effect of pre-operative biopsies on treatment decisions. Secondly, this study is limited to patients undergoing cryoablation, and the results may not be generalisable to patients undergoing other forms of treatment, i.e., radiofrequency ablation or partial nephrectomy. However, we believe the principle remains the same in other treatment modalities where pre-treatment biopsy should be obtained pre-procedure. Finally, owing to the multinational design of the study, there may be heterogeneity in decision-making for patients selected for precryoablation biopsies; hence, the results may not be representative of a wider population or at a specific centre. Nonetheless, we hope this study may increase awareness of the accuracy, safety, efficacy, and advocates for the importance of performing pre-treatment biopsy to reduce the over treatment of benign renal masses.

This multicentre analysis has confirmed the changing trend to adopt image-guided biopsy before treatment over the last decade. The likelihood of obtaining confirmatory histological diagnosis and benign histology decreases significantly when biopsy is performed before treatment as a separate session, and the patient should be consented accordingly during consultation to minimise overtreatment of benign tumours. 


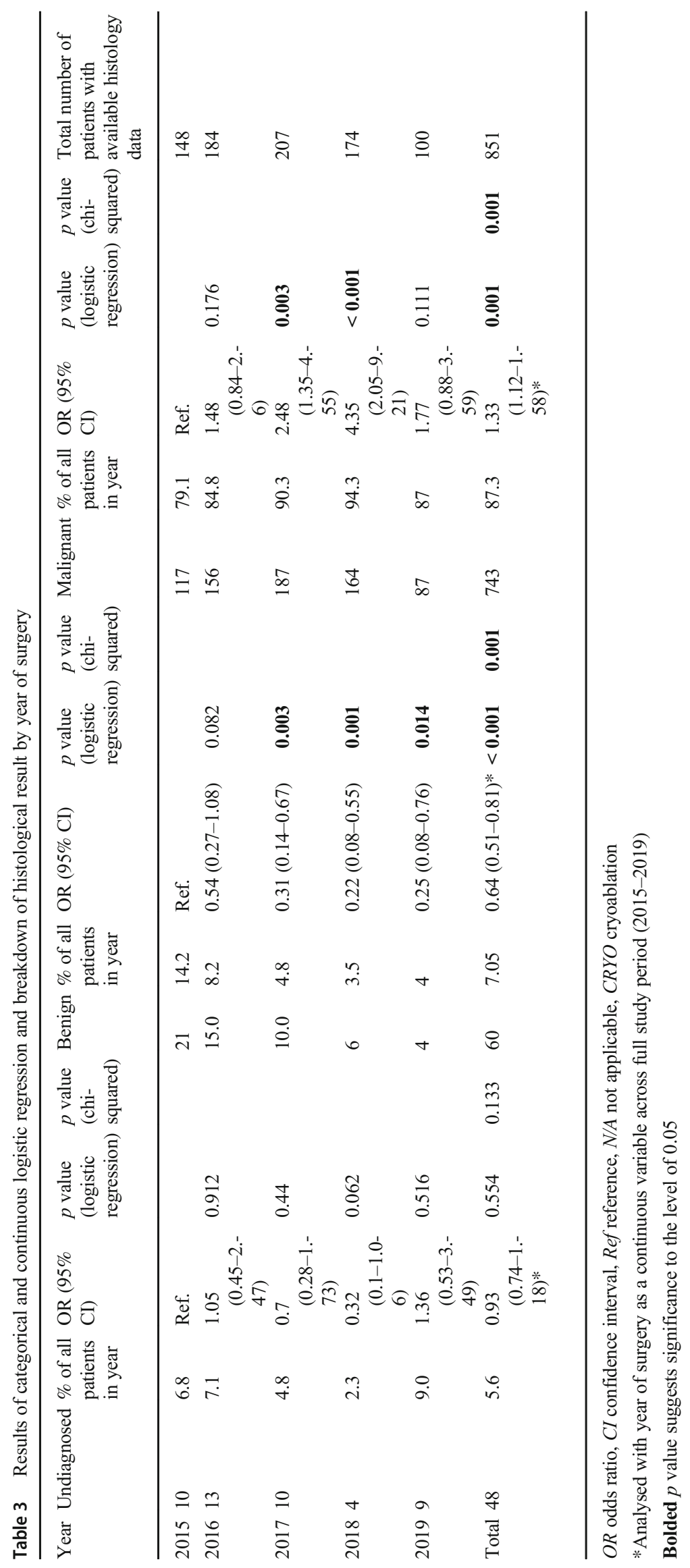


Table 4 Univariate and multivariate logistic regression of factors influencing decision to not perform pre-CRYO biopsy

\begin{tabular}{|c|c|c|c|c|c|c|c|c|c|}
\hline $\begin{array}{l}\text { Clinical and } \\
\text { pathological } \\
\text { characteristic }\end{array}$ & $\begin{array}{l}\text { Univariate } \\
\text { OR }\end{array}$ & $\begin{array}{l}\text { Lower } \\
95 \% \text { CI }\end{array}$ & $\begin{array}{l}\text { Upper } \\
95 \% \text { CI }\end{array}$ & $\begin{array}{l}p \text { value (logistic } \\
\text { regression) }\end{array}$ & $\begin{array}{l}p \text { value (chi- } \\
\text { squared) }\end{array}$ & $\begin{array}{l}\text { Multivariate } \\
\text { OR }\end{array}$ & $\begin{array}{l}\text { Lower } \\
95 \% \text { CI }\end{array}$ & $\begin{array}{l}\text { Upper } \\
95 \% \text { CI }\end{array}$ & $\begin{array}{l}p \text { value (logistic } \\
\text { regression) }\end{array}$ \\
\hline \multicolumn{10}{|l|}{ Age } \\
\hline$<50$ & Ref. & & & & 0.125 & Ref. & & & \\
\hline $50-59$ & 1.28 & 0.64 & 2.57 & 0.489 & & 1.28 & 0.62 & 2.66 & 0.503 \\
\hline $60-69$ & 1.48 & 0.80 & 2.77 & 0.213 & & 1.76 & 0.91 & 3.40 & 0.091 \\
\hline $70-79$ & 1.86 & 1.01 & 3.43 & 0.047 & & 2.17 & 1.13 & 4.18 & 0.020 \\
\hline $80-89$ & 2.05 & 1.03 & 4.10 & 0.042 & & 2.39 & 1.14 & 5.02 & 0.021 \\
\hline $90+$ & \multicolumn{5}{|c|}{ Not estimable ${ }^{\mathrm{a}}$} & \multicolumn{4}{|l|}{ Not estimable $^{\mathrm{a}}$} \\
\hline \multicolumn{10}{|l|}{ Sex } \\
\hline Male & Ref. & & & & 0.291 & Ref. & & & \\
\hline Female & 0.85 & 0.64 & 1.14 & 0.291 & & 0.78 & 0.57 & 1.07 & 0.122 \\
\hline \multicolumn{10}{|l|}{ Race } \\
\hline Caucasian & Ref. & & & & 0.522 & Ref. & & & \\
\hline Asian & 0.53 & 0.17 & 1.65 & 0.275 & & 0.64 & 0.20 & 2.02 & 0.443 \\
\hline Black & 0.87 & 0.32 & 2.33 & 0.776 & & 1.02 & 0.36 & 2.88 & 0.976 \\
\hline \multicolumn{10}{|c|}{ Charlson Comorbidity Index } \\
\hline 0 & Ref. & & & & $<0.001$ & Ref. & & & \\
\hline 1 & 0.81 & 0.52 & 1.28 & 0.375 & & 0.71 & 0.44 & 1.15 & 0.166 \\
\hline $1+$ & 0.45 & 0.32 & 0.61 & $<0.001$ & & 0.40 & 0.28 & 0.57 & $<0.001$ \\
\hline \multicolumn{10}{|l|}{ Obesity } \\
\hline No & Ref. & & & & 0.062 & Ref. & & & \\
\hline Yes & 1.34 & 0.98 & 1.82 & 0.063 & & 1.35 & 0.97 & 1.88 & 0.072 \\
\hline \multicolumn{10}{|l|}{ T-stage } \\
\hline T1a & Ref. & & & & 0.418 & $\mathrm{~N} / \mathrm{A}^{\mathrm{b}}$ & & & \\
\hline $\mathrm{T} 1 \mathrm{~b}$ & 1.16 & 0.81 & 1.65 & 0.419 & & & & & \\
\hline \multicolumn{10}{|c|}{ R.E.N.A.L. score } \\
\hline $4-6$ & Ref & & & & 0.014 & Ref. & & & \\
\hline $7-9$ & 1.20 & 0.90 & 1.60 & 0.211 & & 1.13 & 0.83 & 1.54 & 0.436 \\
\hline $10-12$ & 0.53 & 0.29 & 0.94 & 0.029 & & 0.45 & 0.25 & 0.84 & 0.011 \\
\hline \multicolumn{10}{|c|}{ Tumour diameter } \\
\hline$<2 \mathrm{~cm}$ & Ref. & & & & 0.025 & Ref. & & & \\
\hline $2.1-4 \mathrm{~cm}$ & 1.62 & 1.12 & 2.35 & 0.011 & & 1.34 & 0.90 & 2.01 & 0.150 \\
\hline $4.1-7 \mathrm{~cm}$ & 1.72 & 1.08 & 2.74 & 0.021 & & 1.52 & 0.91 & 2.53 & 0.111 \\
\hline \multicolumn{10}{|c|}{ Solitary functional kidney } \\
\hline No & Ref. & & & & 0.619 & Ref. & & & \\
\hline Yes & 1.19 & 0.59 & 2.41 & 0.619 & & 1.34 & 0.61 & 2.94 & 0.465 \\
\hline \multicolumn{10}{|l|}{ Baseline eGFR } \\
\hline$\geq 90$ & Ref. & & & & 0.924 & Ref. & & & \\
\hline $60-89$ & 0.90 & 0.66 & 1.23 & 0.492 & & 0.82 & 0.58 & 1.14 & 0.230 \\
\hline $45-59$ & 1.10 & 0.71 & 1.72 & 0.659 & & 1.08 & 0.67 & 1.74 & 0.747 \\
\hline $30-44$ & 0.78 & 0.39 & 1.56 & 0.483 & & 1.04 & 0.50 & 2.19 & 0.911 \\
\hline $15-29$ & 0.90 & 0.37 & 2.17 & 0.811 & & 1.22 & 0.48 & 3.10 & 0.678 \\
\hline$<15$ & 0.84 & 0.15 & 4.65 & 0.843 & & 0.85 & 0.15 & 4.94 & 0.857 \\
\hline
\end{tabular}

OR odds ratio, $C I$ confidence interval, $R e f$ reference, $e G F R$ estimated glomerular filtration rate

${ }^{a}$ Small number in this group does not allow adequate estimation of OR

${ }^{\mathrm{b}}$ Excluded from multivariate analysis because of collinearity with tumour diameter

${ }^{\mathrm{c}}$ Excluded from multivariate analysis because of collinearity with solitary kidney

Bolded $p$ value suggests significance to the level of 0.05 
Table 5 Univariate logistic regression of R.E.N.A.L. nephrometry score components influencing decision to not perform pre-cryoablation biopsy

\begin{tabular}{|c|c|c|c|c|}
\hline R.E.N.A.L. component & OR & $95 \% \mathrm{CI}$ & $\begin{array}{l}p \text { value } \\
\text { (logistic } \\
\text { regression) }\end{array}$ & $\begin{array}{l}p \text { value } \\
\text { (chi- } \\
\text { squared) }\end{array}$ \\
\hline \multicolumn{5}{|l|}{ Exophytic/endophytic } \\
\hline $\begin{array}{l}\geq 50 \% \text { exophytic } \\
<50 \% \text { exophytic }\end{array}$ & $\begin{array}{l}\text { Ref. } \\
0.67\end{array}$ & $0.50-0.91$ & 0.010 & \multirow[t]{2}{*}{0.005} \\
\hline Entirely endophytic & 0.55 & $\begin{array}{l}0.37- \\
0.84\end{array}$ & 0.005 & \\
\hline \multicolumn{5}{|l|}{ Nearness to collecting system or sinus (mm) } \\
\hline $\begin{array}{l}\geq 7 \\
>4 \text { and }<7\end{array}$ & $\begin{array}{l}\text { Ref. } \\
1.06\end{array}$ & $0.71-1.57$ & 0.776 & \multirow[t]{2}{*}{$<0.001$} \\
\hline$\leq 4$ & 1.85 & $1.34-2.54$ & $<0.001$ & \\
\hline \multicolumn{5}{|l|}{ Anterior/posterior } \\
\hline $\begin{array}{l}\text { Anterior } \\
\text { Posterior }\end{array}$ & $\begin{array}{l}\text { Ref. } \\
0.48\end{array}$ & $0.34-0.68$ & $<0.001$ & \multirow[t]{2}{*}{$<0.001$} \\
\hline Neither & 0.73 & $0.50-1.04$ & 0.078 & \\
\hline \multicolumn{5}{|l|}{ Location relative to polar lines } \\
\hline $\begin{array}{l}\text { Entirely above or below } \\
\text { Lesion crosses the polar line for }<50 \%\end{array}$ & $\begin{array}{l}\text { Ref. } \\
0.94\end{array}$ & $0.67-1.31$ & 0.709 & \multirow[t]{2}{*}{0.022} \\
\hline $\begin{array}{l}\text { Lesion crosses the polar line for }>50 \% \text {; lesion crosses } \\
\text { the axial line; lesion is between polar lines } \\
\text { Hilar tumour }\end{array}$ & 0.64 & $0.45-0.89$ & 0.008 & \\
\hline $\begin{array}{l}\text { Yes, if tumour touches renal artery or vein } \\
\text { No }\end{array}$ & $\begin{array}{l}\text { Ref. } \\
0.30\end{array}$ & $0.19-0.50$ & $<0.001$ & $<0.001$ \\
\hline
\end{tabular}

$O R$ odds ratio, $C I$ confidence interval, $R e f$ reference

Bolded $p$ value suggests significance to the level of 0.05
Supplementary Information The online version contains supplementary material available at https://doi.org/10.1007/s00330-022-08556-2.

Funding This study has received funding from Boston Scientific.

\section{Declarations}

Guarantor The scientific guarantor of this publication is Mr. Vinson Wai-Shun Chan and Prof. Tze Min Wah.

Conflict of interest Dr. Julien Garnon is a proctor for Boston ScientificBTG and has received fees from Canon Medical, Johnson \& Johnson, and Medtronic for other services. He provided data from Nouvel Hôpital Civil for the registry. Dr. Eric de Kerviler is a consultant to Boston Scientific, speaker for Guerbet and Canon Medical, and provided data from Saint-Louis Hospital for the registry. Dr. Des Acorn is a proctor for Boston Scientific and has provided data from Gartnavel General Hospital for the registry. Prof. Tze Min Wah received research grant from Boston Scientific and education grant from Angiodynamics and was involved in providing data from St. James's University Hospital and supervising data analysis and manuscript writing. The other authors of this manuscript declare no relationships with any companies whose products or services may be related to the subject matter of the article.

Statistics and biometry No complex statistical methods were necessary for this paper.

Informed consent Written informed consent was waived by the institutional review board.
Ethical approval Institutional review board approval was not required as per local guidelines of each centre.

\section{Methodology \\ - retrospective \\ - observational \\ - multicentre study}

Open Access This article is licensed under a Creative Commons Attribution 4.0 International License, which permits use, sharing, adaptation, distribution and reproduction in any medium or format, as long as you give appropriate credit to the original author(s) and the source, provide a link to the Creative Commons licence, and indicate if changes were made. The images or other third party material in this article are included in the article's Creative Commons licence, unless indicated otherwise in a credit line to the material. If material is not included in the article's Creative Commons licence and your intended use is not permitted by statutory regulation or exceeds the permitted use, you will need to obtain permission directly from the copyright holder. To view a copy of this licence, visit http://creativecommons.org/licenses/by/4.0/.

\section{References}

1. Bray F, Ferlay J, Soerjomataram I, Siegel RL, Torre LA, Jemal A (2018) Global cancer statistics 2018: GLOBOCAN estimates of incidence and mortality worldwide for 36 cancers in 185 countries. CA Cancer J Clin 68:394-424 
2. Ferlay J, Colombet M, Soerjomataram I et al (2018) Cancer incidence and mortality patterns in Europe: estimates for 40 countries and 25 major cancers in 2018. Eur J Cancer 103:356-387

3. Novara G, Ficarra V, Antonelli A et al (2010) Validation of the 2009 TNM version in a large multi-institutional cohort of patients treated for renal cell carcinoma: are further improvements needed? Eur Urol 58:588-595

4. van Oostenbrugge TJ, Fütterer JJ, Mulders PFA (2018) Diagnostic imaging for solid renal tumors: a pictorial review. Kidney Cancer (Clifton, Va) 2:79-93

5. Kim JH, Li S, Khandwala Y, Chung KJ, Park HK, Chung BI (2019) Association of prevalence of benign pathologic findings after partial nephrectomy with preoperative imaging patterns in the United States from 2007 to 2014. JAMA Surg 154:225-231

6. Richard PO, Jewett MA, Bhatt JR et al (2015) Renal tumor biopsy for small renal masses: a single-center 13-year experience. Eur Urol 68:1007-1013

7. Richard PO, Lavallée LT, Pouliot F et al (2018) Is routine renal tumor biopsy associated with lower rates of benign histology following nephrectomy for small renal masses? J Urol 200:731-736

8. Widdershoven CV, Aarts BM, Zondervan PJ et al (2020) Renal biopsies performed before versus during ablation of $\mathrm{T} 1 \mathrm{renal}$ tumors: implications for prevention of overtreatment and follow-up. Abdom Radiol. https://doi.org/10.1007/s00261-020-02613-4

9. Smaldone MC, Kutikov A, Egleston BL et al (2012) Small renal masses progressing to metastases under active surveillance: a systematic review and pooled analysis. Cancer 118:997-1006

10. Ljungberg BLA, Bensalah K, Bex A et al (2020) EAU guidelines: renal cell carcinoma | Uroweb. EAU Guidelines Office, Arnhem, The Netherlands. http://uroweb.org/guidelines/compilations-of-allguidelines/. Available via https://uroweb.org/guideline/renal-cellcarcinoma. Accessed 15 August 2020

11. Marconi L, Dabestani S, Lam TB et al (2016) Systematic review and meta-analysis of diagnostic accuracy of percutaneous renal tumour biopsy. Eur Urol 69:660-673

12. Richard PO, Martin L, Lavallée LT et al (2018) Identifying the use and barriers to the adoption of renal tumour biopsy in the management of small renal masses. Canadian Urological Association journal $=$ Journal de l'Association des urologues du Canada 12:260-266

13. (2020) EuRECA - European Registry for Renal Cryoablation Available via https://www.eureca-registry.com/. Accessed 17th October 2020

14. Amin MB, Greene FL, Edge SB et al (2017) The eighth edition AJCC cancer staging manual: continuing to build a bridge from a population-based to a more "personalized" approach to cancer staging. CA Cancer J Clin 67:93-99

15. Chan VW, Lenton J, Smith J et al (2021) Multimodal image-guided ablation on management of renal cancer in Von-Hippel-Lindau syndrome patients from 2004 to 2021 at a specialist centre: A longitudinal observational study. Eur J Surg Oncol. https://doi.org/10. 1016/j.ejso.2021.10.022

16. Teoh JY-C, Ong WLK, Gonzalez-Padilla D et al (2020) A global survey on the impact of COVID-19 on urological services. Eur Urol 78:265-275

17. Chan VW-S, Chiu PK-F, Yee C-H, Yuan Y, Ng C-F, Teoh JY-C (2021) A Systematic review on COVID-19: urological manifestations, viral RNA detection and special considerations in urological conditions. World J Uro 1:1-12
18. Chan VW-S, Ng HH-L, Rahman L et al (2021) Transmission of severe acute respiratory syndrome coronavirus 1 and severe acute respiratory syndrome coronavirus 2 during aerosol-generating procedures in critical care: a systematic review and meta-analysis of observational studies. Crit Care Med 49

19. Charlson ME, Pompei P, Ales KL, MacKenzie CR (1987) A new method of classifying prognostic comorbidity in longitudinal studies: development and validation. J Chronic Dis 40:373-383

20. Levey AS, Bosch JP, Lewis JB, Greene T, Rogers N, Roth D (1999) A more accurate method to estimate glomerular filtration rate from serum creatinine: a new prediction equation. Modification of Diet in Renal Disease Study Group. Ann Intern Med 130:461-470

21. Kutikov A, Uzzo RG (2009) The R.E.N.A.L. nephrometry score: a comprehensive standardized system for quantitating renal tumor size, location and depth. J Urol 182:844-853

22. von Elm E, Altman DG, Egger M, Pocock SJ, Gøtzsche PC, Vandenbroucke JP (2007) The Strengthening the Reporting of Observational Studies in Epidemiology (STROBE) statement: guidelines for reporting observational studies. Lancet 370:14531457

23. Veltri A, Garetto I, Tosetti I et al (2011) Diagnostic accuracy and clinical impact of imaging-guided needle biopsy of renal masses. Retrospective analysis on 150 cases. Eur Radiol 21:393-401

24. Volpe A, Mattar K, Finelli A et al (2008) Contemporary results of percutaneous biopsy of 100 small renal masses: a single center experience. J Urol 180:2333-2337

25. Maturen KE, Nghiem HV, Caoili EM, Higgins EG, Wolf JS Jr, Wood DP Jr (2007) Renal mass core biopsy: accuracy and impact on clinical management. AJR Am J Roentgenol 188:563-570

26. Shannon BA, Cohen RJ, de Bruto H, Davies RJ (2008) The value of preoperative needle core biopsy for diagnosing benign lesions among small, incidentally detected renal masses. J Urol 180: 1257-1261 discussion 1261

27. Lane BR, Abouassaly R, Gao T et al (2010) Active treatment of localized renal tumors may not impact overall survival in patients aged 75 years or older. Cancer 116:3119-3126

28. Hollingsworth JM, Miller DC, Daignault S, Hollenbeck BK (2007) Five-year survival after surgical treatment for kidney cancer: a population-based competing risk analysis. Cancer 109:1763-1768

29. Pierorazio PM, Johnson MH, Ball MW et al (2015) Five-year analysis of a multi-institutional prospective clinical trial of delayed intervention and surveillance for small renal masses: the DISSRM registry. Eur Urol 68:408-415

30. Chan VW, Tan WS, Leow JJ et al (2021) Delayed surgery for localised and metastatic renal cell carcinoma: a systematic review and meta-analysis for the COVID-19 pandemic. World J Urol. https://doi.org/10.1007/s00345-021-03734-1:1-9

31. Sisul DM, Liss MA, Palazzi KL et al (2013) RENAL nephrometry score is associated with complications after renal cryoablation: a multicenter analysis. Urology 81:775-780

32. Reddy UD, Pillai R, Parker RA et al (2014) Prediction of complications after partial nephrectomy by RENAL nephrometry score. Ann R Coll Surg Engl 96:475-479

Publisher's note Springer Nature remains neutral with regard to jurisdictional claims in published maps and institutional affiliations. 